\title{
Does Assessment Method Affect Employee's Performance and Productivity?-An Empirical Study in Bangladesh
}

\author{
AKM Mominul Haque Talukder \\ School of Business, North South University, Dhaka 1229, Bangladesh \\ momin@northsouth.edu
}

\begin{abstract}
The research investigates various assessment methods used in one of the telecom firm's recruitment and selection process and its impact on productivity and performance of employee. Data were collected based on structured questionnaires. Results indicate that cognitive ability tests, personality tests, job knowledge tests, and medical tests are significantly positively related with employee's productivity and performance of employees. Conversely, resume and cover letter has no relationship with employee's performance and productivity. The study further suggests that incorporating these assessment methods critically may render telecom industry with the potent to leverage employee's performance and productivity.
\end{abstract}

Keywords: Assessment, selection, productivity, performance

\section{Introduction}

The goal of an assessment method is to identify the job candidates who would make good hires, and to screen out people who would make poor hires (Phillips \& Gully, 2009). Success of a company depends on the strategic human resource staffing process where recruitment and selection process is considered to be the most vital. A well designed assessment system can increase the number of good hires and reduce the number of bad hires an organization makes. For jobs in which there is a meaningful performance difference between high and low performers, identifying and hiring the best candidates can dramatically increase productivity and performance (Phillips \& Gully, 2009). The choice of which candidates to hire should be based on who is likely to experience the greatest job success and who can best meet the overall hiring goals for the position, including job performance, promotability, the cost of the total reward package, etc. Assessment methods tend to become more complex the more critical a job is to the firm and the more complex the required competencies are. If a job is difficult to do well, then it is even more important to recruit strategically, assess job candidates carefully, and to choose new hires wisely.

A good assessment system which hires good employees, as a result creates a competitive advantage which competitors cannot have easily. Proper employees hired at the right time for the right place ensures proper decisions taken at the right time, hence may increase efficiency and therefore productivity. The greater the return on the investment in an assessment method, the greater the assessment method's value (Phillips \& Gully, 2009). One assessment method may be slightly superior to another in identifying the best candidates, but if it costs exceeds the gain the organization of hiring these slightly better candidates, then the other method may be the better choice. The longer good performers stay with the company, the grater the return on company's investment. Research also shows that people who have frequently changed jobs in the past are more likely to do so in the future (Judge \& Watanabe, 1995).

Attempts are made to analyze the impacts of resume or cover letter, cognitive ability tests, personality assessment, job knowledge test and medical test while considering productivity and performance being the two dependent variables that may be influenced by the said dependent variables. These dependent and independent variables are selected from the various studies of the strategic staffing across the organizations. Successful private and public sector organizations must have robust human capital strategies that enable organizations to meet current and future business needs. There is perhaps no more important topic in human resource management than employee selection (Bohlander \& Snell, 2004). It is true that organizations succeed or fail on the basis of talents of employees, and then managers directly influence that success by the people they hire. Regardless of whether the company is large or small hiring the best and the brightest employee lays a strong foundation for excellence. An employment test is an objective and standardized 
measure of a sample of behavior that is used to gauge a person's knowledge, skills, abilities, and other characteristics (KSAOs) in relation to other individuals (Bohlander \& Snell, 2004). It is surprising that the effect of various assessment methods on organizational performance and productivity has not been examined more thoroughly within a work context in local organizations in Bangladesh. In this research, attempts have been made to address the discrepancy in literature review by examining the impact of assessment methods on performance and productivity of employees in telecom firm.

\section{Review of Literature}

Performance management includes activities to ensure that goals are consistently being met in an effective and efficient manner. Performance management can focus on performance of the organization, a department, processes to build a product or service, employees, etc. After strategic planning, writing a job description, person specification, sourcing candidates and recruiting, the next step in the staffing process is assessing the degree to which job candidates possess the required qualifications and characteristics to perform the job well. Once you have a pool of applicants, the next step is to select the best candidates for the job. Selecting the right employees is important for three main reasons: performance, costs, and legal obligations (Dessler, 2006). First organization's own performance always depends in part on its subordinates. Employees with the right skills will do a better job for you and the company. Employees without these skills or who are abrasive or obstructionist won't perform effectively and your own performance and the firm's will suffer. The time to screen out undesirables is before they are in the door, not after. Second, it is important because it is costly to recruit and hire employees. Hiring and training even a clerk cost 5000 or more in fees and supervisory time. The total cost of hiring a manager could be 10 times as high once you add search fees, interviewing time, reference checking, and travel and moving expenses. Third, it is important because of two legal implications of incompetent hiring. First, equal employment laws require non-discriminatory selection procedures for protected groups and second, courts might find the employer liable when employees with criminal records or other problems use access to customers' home to commit crimes.

Resume and Cover Letter: The first introduction of the applicant to the organization is often a resume and a cover letter (Heneman \& Judge, 2008). Resumes and cover letters have historically been a core part of the hiring process. Applicants volunteer information about themselves and their interest in the position in a cover letter, and provide a résumé summarizing their relevant education and work and non-work experiences (Phillips \& Gully, 2009). One of the biggest drawbacks of resumes and cover letter is that applicants do not use the same format or include the same information in their resumes, which can make it difficult to compare them. Experts estimates 10 percent to 30 percent of job seekers shade the truth or flat out lie on their resume, particularly in the areas of education, previous compensation, reason for leaving previous jobs and previous job titles and accomplishments (Phillips \& Gully, 2009). A wealth of research has demonstrated that biodata provide employers with reliable information that can be used to make accurate predictions of future job performance (Mumford, Constanza, Connelly, \& Johnson, 1996). Some of the criteria of which biodata have been shown to be predictive include absenteeism, proficiency ratings, delinquency, substance abuse, promotion, achievement, accidents (Stokes \& Cooper, 1994), success in the military (Parish \& Drucker, 1957), job placement success (Harvey-Cook \& Taffler, 2000), turnover (Barrick \& Zimmerman, 2005), training performance and customer service orientation (Carreher, Carreher, \& Mintu-Wimsatt, 2005). From the above it can be hypothesized that:

H1: Resume and cover letter are positively related with performance and productivity of the employees in the organization.

Cognitive Ability Test: Cognitive ability tests assess a person's general mental abilities including their verbal and mathematical reasoning logic and perceptual abilities. Research shows that, individuals with higher level of general mental ability acquire new information more easily and more quickly and are able to use that information more effectively (Phillips \& Gully, 2009). Research supports the idea that cognitive ability is more important in complex jobs, when individuals are new to the job, and when there are changes in the workplace that require workers to learn new ways of performing their jobs (Hunter, 1986). Ability tests are measures that assess an individual's capacity to function in a certain way. Survey reveals that between $15 \%$ and $20 \%$ of organizations use some sort of ability test in selection decision (Rowe, et al., 1994). Cognitive ability tests 
assess abilities involved in thinking, including perception, memory, reasoning, verbal and mathematical abilities, and the expression of ideas. Research shows that measures of specific cognitive abilities, such as verbal, quantitative, reasoning and son on, appear to reflect general intelligence. (Ree \& Earles, 1991). So it can be hypothesized that:

H2: Cognitive ability test is positively related with performance and productivity of the employees in the organization.

Personality Test: General cognitive ability was found to be the best single predictor of job performance in both the United States and Europe for all occupations (Bertua, Anderson, \& Salgado, 2005) and hundreds of validity studies have been conducted in the last 80 years. However, for many years, personality measures were considered poor predictors of organizational behaviors. This belief was mainly due to the small correlations found between personality characteristics and the organizational criteria (e.g., job performance) and in part due to the strong criticisms made by the situationist view of personality.

Despite continuing challenges to personality testing in personnel selection major reviews of personality tests have pointed out that they have validity in predicting job performance (Ones, Dilchert, Viswesvaran, \& Judge, 2007; Tett \& Christiansen, 2007). In the first promising review on the relationship between personality and job performance, Barrick and Mount (1991) claimed that of the five personality constructs (e.g., extraversion, conscientiousness, agreeableness, emotional stability, and openness to experience), conscientiousness was the best predictor for a variety of job settings and performance criteria. Similarly, others (Barrick, Mount, \& Judge, 2001; Ones, Viswesvaran, \& Schmidt, 1993) also pointed out that conscientiousness, emotional stability, and integrity were valid predictors of job performance. Personality assessment can have low to moderate validity (ranging from -.13 to .33), which improves when the assessment is well matched with specific criteria (Morgeson, et al, 2007). Conscientiousness and emotional stability seem to predict overall performance for a wide range of jobs (Barrick and Mount, 2005). The big five are very stable over time and seem to be determined in part by genetics (Costa and McCrae, 1992). Personality tests are very easy to use but applicants often react too poorly to them (Rosse, et al, 1996). So it can be hypothesized that:

H3: Personality test is positively related with performance and productivity of the employees in the organization.

Job Knowledge Test: Job knowledge test measures a candidate' knowledge (often technical) required by a job. These tests are often in multiple choice, essay or checklist format and can assess either the candidates' knowledge of a job's duty or experience level with regard to job's tasks, tools, and processes. Job knowledge test generally result in minimum adverse impact and can be highly valid for complex jobs. Government agencies and licensing boards usually develop job knowledge tests, a type of achievement tests designed to measure a person's level of understanding about a particular job (Bohlander \& Snell, 2004). Most civil service examinations, for example, are used to determine whether an applicant possesses the information and understanding that will permit placement on the job without further training. There has been less research on the validity of job knowledge tests than most other selection measures. A recent study, however, provided relatively strong support for the validity of job knowledge tests. A meta-analytic review of 502 studies indicated that the "true" validity of job knowledge tests in predicting job performance is .45 . These validities were found to be higher for complex jobs and when job and test content was similar (Heneman \& Judge, 2006). So it can be hypothesized that:

H4: Job knowledge test is positively related with performance and productivity of the employees in the organization.

Medical Test: There are several reasons for preemployment medical test (Dessler, 2006). One is to verify that the applicant meets the physical requirements of the position. Another is to discover any medical limitations. You should take into account in placing the applicant. The exam will also establish a record and baseline of applicant's health for future insurance or compensation claims. By identifying health problems the exam can also reduce absenteeism and accidents and of course detect communicable diseases that may be unknown to the applicant. A medical exam is generally given to ensure that the health of an applicant is 
adequate to meet the job requirements. It also provides a baseline against which subsequent medical examinations can be compared and interpreted (Bohlander \& Snell, 2004). Based on the above discussion following hypothesis can be reached. So it can be hypothesized that:

H5: Medical test is positively related with performance and productivity of the employees in the organization.

Conceptual Model: A model is tested that derived from review of the literature integrating theory and research relating to different assessment methods including resume and cover letter, cognitive ability test, personality assessment, job knowledge test, medical test and their relationship to employee's performance and productivity. Recruiting right people in wrong place has been shown to be an enabling factor for decreased level of performance and productivity in the workplace. Conversely, recruiting right people, right place, right time with right knowledge, skills and abilities not only increase the employee performance but also it will elevate productivity in order to have sustained competitive advantage for the organization.

\section{Figure 1: Conceptual framework of research variables and their relationships}

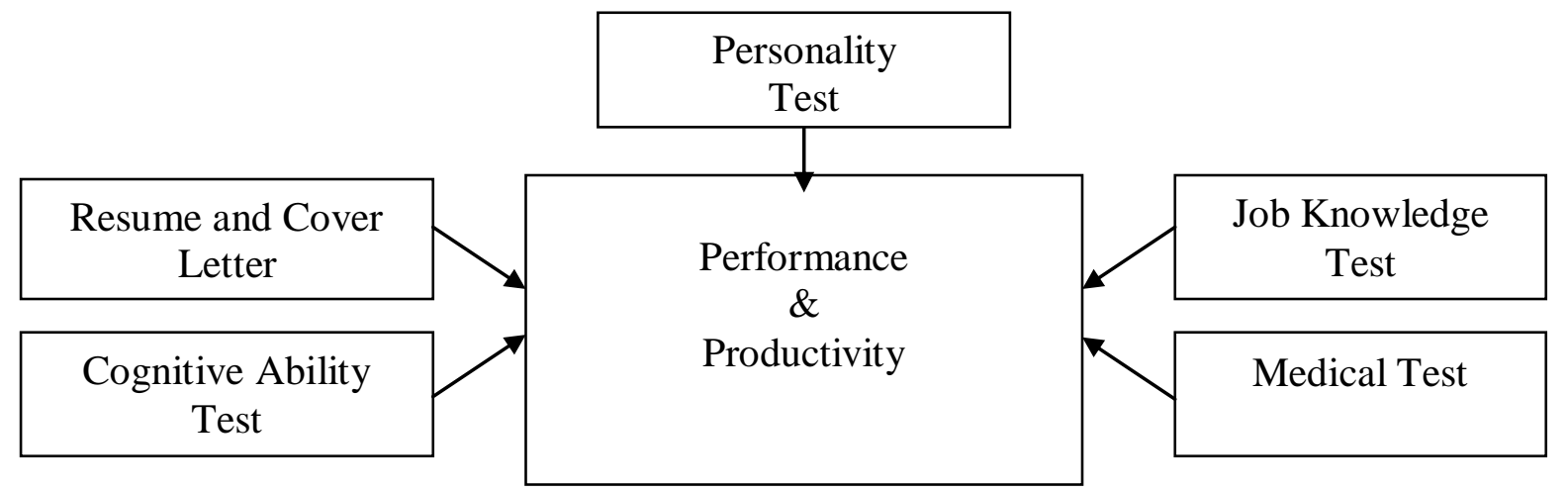

\section{Methodology}

The participants were full-time male and female employees from a leading telecom firm (formerly it was Warid now airtel) based in Dhaka, Bangladesh. A total of 108 respondents participated in the study. All of them were managerial employees since the items in the questionnaire were assumed appropriate for them. Of them, $65 \%$ were male and 35\% were female employees. The age ranges from 25 years to 45 years. The education level was bachelor to master's degree. The study adopted a convenience sampling approach to select the participants. A mail survey was used in July 2009 to August 2009 for collecting data. With regard to questionnaire mailing, 45 surveys were undeliverable because of missing address or had moved to unknown locations. Deducting the undeliverable from the original 200 mailed, the valid mailing was 155 surveys, from which 132 responses were received. Of the surveys completed and returned, only 108 were usable. The effective response rate was approximately 66\%. According to Aaker, Kumar and Day (2001) the response rate for a mail survey, without an appropriate follow up procedure, is less than $20 \%$, thus the response rate of this study is considered more acceptable. All the questions in the survey questionnaire are of 5-point Likert scale ranging from 1 (Strongly Disagree) to 5 (Strongly Agree). All the participants were given a letter, attached to the questionnaire, from the researcher explaining the context of the research. No information was asked on the identity or contact information of the respondents. The instrument consists of 35 items with seven variables: work environment, emotions, hostility, fatigue, joviality, attentiveness and job satisfaction. All items used 5-point Likert scales ranging from highly disagree (1) to highly agree (5).

\section{Results and Discussion}

Hypothesis 1 states that resume and cover letter are positively related with performance and productivity of the employees in the organization. The study finds (Table 1) no relationship of resume and cove letter with performance and productivity of the employees. Hypothesis 2 states that cognitive ability test is positively related with performance and productivity of the employees in the organization. Thus the hypothesis is 
rejected. The study indicates significant positive relationship of cognitive ability test with productivity $\left(\mathrm{r}=.5^{* *}, p<.01\right)$ and performance $\left(\mathrm{r}=.8^{* *}, p<.01\right)$ of employees. Hence the hypothesis is accepted.

Table 1: Descriptive statistics, reliabilities and correlation of variables

\begin{tabular}{llllllllll}
\hline Variables & Mean & SD & $\mathbf{1}$ & $\mathbf{2}$ & $\mathbf{3}$ & $\mathbf{4}$ & $\mathbf{5}$ & $\mathbf{6}$ & $\mathbf{7}$ \\
\hline 1. Productivity & 4.71 & .44 & $(.8)$ & & & & & & \\
2. Performance & 4.21 & .26 & $.4^{* *}$ & $(.63)$ & & & & & \\
3. Resume \& Cover Letter & 4.23 & .27 & -.15 & -.3 & $(.98)$ & & & & \\
4. Cognitive Ability Test & 4.29 & .37 & $.5^{* *}$ & $.8^{* *}$ & -.2 & $(.51)$ & & & \\
5. Personality & & & & & & & & & \\
Assessments & 4.34 & .31 & $.5^{* *}$ & $.8^{* *}$ & -.2 & $.96^{* *}$ & $(.72)$ & & \\
6. Job Knowledge Test & 4.32 & .27 & $.44^{* *}$ & $.81^{* *}$ & -.2 & $.38^{* *}$ & $.39^{* *}$ & $(.5)$ & \\
7. Medical Test & 4.40 & .38 & $.39^{* *}$ & $.53^{* *}$ & -.18 & $.5^{* *}$ & $.44^{* *}$ & $.38^{* *}$ & $(.43)$ \\
\hline
\end{tabular}

$N=108,{ }^{* *} p<.01$

Hypothesis 3 states that personality test is positively related with performance and productivity of the employees in the organization. The research notices significant positive relationship of cognitive ability test with productivity $\left(\mathrm{r}=.5^{* *}, p<.01\right)$ and performance $\left(\mathrm{r}=.8^{* *}, p<.01\right)$ of employees. Hence the hypothesis is accepted. Hence the hypothesis is accepted. Hypothesis 4 states that job knowledge test is positively related with performance and productivity of the employees in the organization. The study represents significant positive relationship of cognitive ability test with productivity $\left(\mathrm{r}=.44^{* *}, p<.01\right)$ and performance $\left(\mathrm{r}=.81^{* *}\right.$, $p<.01)$ of employees. Hence the hypothesis is accepted. Hence the hypothesis is accepted. Hypothesis 5 states that medical test is positively related with performance and productivity of the employees in the organization. The study demonstrates significant positive relationship of cognitive ability test with productivity $\left(\mathrm{r}=.39^{* *}, p<.01\right)$ and performance $\left(\mathrm{r}=.53^{* *}, p<.01\right)$ of employees. Hence the hypothesis is accepted.

All hypothesis including 1 to 5 predicted positive relationship between the variables. But the results found positive relationship of all variables with productivity and performance of employees in the studied firm. Only negative relationship was observed between resume \& cover letter with productivity and performance of employees. This can be justified by Mitchel \& Klimoski (1982) where they criticized resume for lack of stability or loss of predictive validity over time. Resumes are also criticized for limited generalizability. It also has been perceived as having more limited use than cognitive abilities exams because they are often custommade for individual organization (Hunter and Hunter, 1984). The study reported that a cognitive ability test is a good indicator of productivity and performance of employees. This can be rationalized by Salgado et al (2003) where they estimated true validity of general cognitive ability to be roughly 0.5 which is quite reasonable validity coefficient. They noted that cognitive ability tests are among the most valid methods of selection and appeared to generalize across all organizations, all job types, and all types of applications; thus, they are likely to be valid in virtually any selection context. Hunter (1986) suggested cognitive ability test relatively high average validities for many occupational groups. The validity is particularly high for complex job but even for simple jobs the validity is positive. Research has shown that most of the effect of cognitive ability tests is due to the fact that intelligent employees have greater job knowledge.

The research found positive relationship of personality test with productivity and performance of the employees. Major reviews of personality tests have pointed out that they have validity in predicting job performance (Ones, Dilchert, Viswesvaran, \& Judge, 2007; Tett \& Christiansen, 2007). In the first promising review on the relationship between personality and job performance, Barrick and Mount (1991) claimed that of the five personality constructs (extraversion, conscientiousness, agreeableness, emotional stability, and openness to experience), conscientiousness was the best predictor for a variety of job settings and performance criteria. Similarly, others (Barrick, Mount, \& Judge, 2001; Hogan, Hogan, \& Roberts, 1996; Ones, Viswesvaran, \& Schmidt, 1993; Salgado, 1997) also pointed out that conscientiousness, emotional stability, and integrity were valid predictors of job performance. The study indicated positive relationship of job knowledge tests with productivity and performance of employees in the firm. Dye et al (1993) reported "true" 
validity of job knowledge tests in predicting job performance is 0.45 . These validities were found to be higher for complex jobs and when job and test content was similar. The study found positive relationship of medical test with productivity and performance of employees. This can be supported by Walter et al (1997) that physical abilities such as strength and endurance tend to be good predictors not only of performance, but of accidents and injuries.

\section{Conclusion}

Managers at any level are now taking such considerations while making decisions about their candidate selection in order to maintain an effective and sustainable talent pool that will act as a competitive advantage and ensure a more strategic human resource management process. However, the assessment method being implemented needs to be updated time to time in order to align with changing requirements and conditions. It should also take into consideration that it does not discriminate against a certain group of candidates which will lead to negative spillover effects. To uphold the company image, it is vital that throughout the assessment process, the candidates are treated fairly and respectfully. It is also important that though the inclusion of many methods of assessments increases the positive impact for the company, it also makes it lengthy and extensive. By making the assessment method less lengthy, it will be able to attract more candidates in the future.

Constant feedback from candidates, employees and management will sustain the stability of internal assessment methods. In order to survive and thrive in a competing marketplace along with other competitors such as Grameen Phone, Banglalink, City Cell, Roby and so on, airtel could maintain these effective assessment methods consistently to attract potential talent pool while retaining high performer. To avoid adverse impact, a combination of both multiple hurdle and compensatory assessment methods is required to capture those candidates who will socialize themselves both in person-job fit and person-organization fit. The firm also needs to consider the legal issues involved in assessing the candidates to avoid legal actions and maintain fairness. Assessment centre will assist the whole process by giving candidates experience of a microcosm of the job while testing them on work-related activities as individuals and in groups. In conclusion, these methods help to screen out bad hires to select most potential finalists and that lead to hire long term, productive, and well performing employees who are easier to train and retain. This in turn reduces costs of employee turnover, provides a low selection ratio and maintains a competitive pool of talent inside the company. The study have had certain limitations in terms of framing standard questionnaire, smaller sample size and not selecting participants from different type of companies, and not eliciting generalization. This might be an epitome for human resource management researchers to have insight about the impact of assessment methods that might influence present and more importantly future productivity and performance of employees significantly. Hiring managers could conduct assessment methods objectivity to retain high performers and to eliminate low performers to capitalize best talent in the organization.

\section{References}

Aaker, D. A., Kumar, V. \& Day, G. S. (2001). Marketing Research, ( $7^{\text {th }}$ Ed). John Wiley and Sons New York, NY.

Barrick, M. R. \& Mount, M. K. (1991). The Big Five Personality Dimensions and Job Performance: A metaanalysis. Personnel Psychology, 44(1), 1-26.

Barrick, M. R., Mount, M. K. \& Judge, T. A. (2001). The FFM personality dimensions and job performance: Meta-analysis. Invited submission to a special selection issue of International Journal of Selection and Assessment, 9(1), 9-30.

Barrick, M. R. \& Mount, M. K. (2005). Yes, Personality Matters: Moving on to More Important Matters, Human Performance, 18(4), 359-372.

Barrick, M. R. \& Zimmerman, R. D. (2005). Reducing Voluntary, Avoidable Turnover through Selection. Journal of Applied Psychology, 90, 159-166.

Bertua, C., Anderson, N. \& Salgado, J. F. (2005). The Predictive Validity of Cognitive Ability Tests: A UK metaanalysis. Journal of Occupational and Organizational Psychology, 78, 307-409.

Bohlander, G. \& Snell, S. (2004). Human Resource Management, 13'th eds. Thomson International, 184-205. 
Carreher, S. M., Carreher, S. C. \& Mintu-Wimsatt, A. (2005). Customer Service Management in Western and Central Europe: A concurrent validation strategy in entrepreneurial financial information services organizations. Journal of Business Strategies, 22, 41-54.

Costa, P. T. \& McCrae, R. R. (1992) Revised NEO Personality Inventory (NEO-PI-R) and NEO Five Factor Inventory (NEO-FFI) Professional Manual. Odessa, FL: Psychological Assessment Resources.

Dessler, G. (2008). Human Resource Management, 11 ${ }^{\text {th }}$ eds., Pearson Education International. 210-238.

Dye, D. M, Reck, M \& McDaniel, M. A. (1993). The Validity of Jon Knowledge Measures, International Journal of Selection and Assessment, 1(3), 153-157.

Harvey-Cook, J. \& Taffler, R. (2000). Biodata in Professional Entry-Level Selection: Statistical scoring of common format applications. Journal of Occupational \& Organizational Psychology, 73, 103-118.

Heneman, G. H. \& Judge, T. A. (2006). Staffing Organizations, 5 th Ed, McGraw-Hill International, 428-429.

Hogan, R., Hogan, J. \& Roberts, B. W. (1996). Personality Measurement and Employment Decisions. American Psychologist, 51(5), 469-477.

Hunter, J. E. \& Hunter, R. F. (1984). Validity and Utility of Alternate Predictors of Job Performance. Psychological Bulletin, 96, 72-98.

Hunter, J. E. (1986). Cognitive Ability, Cognitive Aptitudes, Job Knowledge, and Job Performance, Journal of Vocational Behavior, 29(3), 340-362.

Judge, T. A., \& Watanabe, S. (1995). Is the Past Prologue? A Test of Ghiselli's Hobo Syndrome. Journal of Management, 21, 211-229

Mitchell, T. W. \& Klimoski, R. J. (1982). Is it Rational to be Empirical? A test of methods for scoring biographical data. Journal of Applied Psychology, 67(4), 411-418.

Morgeson, F. P., Campion, M. A, Dipboye, R L, Hollenbeck, J. R, Murphy, K, \& Schmitt, N. (2007). Reconsidering the Use of Personality Tests in Personnel Selection Contexts, Personnel Psychology, 60(3), 683-729.

Mumford, M., Constanza, D. P., Connelly, M. S. \& Johnson, J. F. (1996). Item Generation Procedures and Background Data Scales: Implications for construct and criterion-related validity. Personnel Psychology, 49(2), 361-399.

Ones, D. S., Viswesvaran, C. \& Schmidt, F. L. (1993). Comprehensive Meta-Analysis of Integrity Test Validities: Findings and implications for personnel selection and theories of job applications. Palo Alto, CA: Consulting Psychologists Press, 311-340.

Ones, D. S., Dilchert, S., Viswesvaran, C., \& Judge, T. (2007). In support of personality assessments in organizational settings. Personnel Psychology, 60(4), 995-1027.

Parish, J. \& Drucker, A. (1957). Personnel research of Officer Candidate School, USA TAGO Personnel Research Branch Technical Research Report. 117.

Phillips, J. M., \& Gully, S. M. (2009). Strategic Staffing, $1^{\text {st }}$ ed. Pearson Education International, 243-359.

Ree, M. J. \& Earles, J. A. (1991). The Stability of g across different methods of estimation, Intelligent, 15, 271278.

Rosse, J. G., Miller J. L. \& Ringer, R. C. (1996). The Deterrent Value of Drug and Integrity Testing, Journal of Business and Psychology, 10(4), 477-485.

Rowe, P. M., Williams, M. C. \& Day, A. L. (1994). Selection Procedures in North America, International Journal of Selection and Assessment, 2, 74-79.

Salgado, J. F. (1997). The Five Factor Model of Personality and Job Performance in the European Community. Journal of Applied Psychology, 82, 30-43.

Salgado, J. F., Anderson, N., Moscoso, S., Bertua, C., De Fruyt, F. \& Rolland, J. P. (2003). A Meta-Analytic Study of GMA Validity for Different Occupations in the European Community. Journal of Applied Psychology, $88,1068-1081$.

Stokes, G. S. \& Cooper, L. A. (1994). Selection Using Biodata: Old notions revisited. In: Stokes, G. S., Mumford, M.D. and Owens, W.A. (Eds), Biodata Handbook: Theory, research, and applications. Palo Alto, CA: Consulting Psychologists Press, 311-340.

Tett, R. P. \& Christiansen, N. D. (2007). Personality Tests at the Crossroads: A response to Morgeson, Campion, Dipboye, Hollenbeck, Murphy, and Schmitt. Personnel Psychology, 60(4), 967-993.

Walter, C. B., Sager, C. E., Peterson, N.G., Oppler, S. H. \& Rosse, R. L. (1997). Personnel Selection, Annual Review of Psychology, 48, 299-3. 